\title{
Curriculum and the Role of Research: Report of the ICME 12 Survey Team*
}

\section{Currículo e o Papel da Pesquisa: Relatório para o ICME 12}

\author{
Gail Burrill $^{* *}$ \\ Glenda Lappan ${ }^{* * *}$ \\ Funda Gonulates $^{* * * *}$
}

\begin{abstract}
The survey team collected information on the development and use of curriculum from 11 diverse countries around the world. The data shows that a common set of mathematics learning goals are established in almost all countries. However, only a few countries report a substantial role for research in designing and monitoring the development of their curriculum. The data also suggests great variation among countries at the implementation level.
\end{abstract}

Keywords: Standards. Curriculum. Technology. Tracking. Textbooks. Research and Teacher Support.

\section{Resumo}

A equipe de pesquisa coletou informações sobre o desenvolvimento e o uso do currículo de 11 diferentes países ao redor do mundo. Os dados mostram que há uma base comum e que metas de aprendizagem matemática são estabelecidas em quase todos os países. No entanto, apenas alguns países consideram importante o papel da pesquisa na elaboração e acompanhamento do desenvolvimento de seu currículo. Os dados também indicam grande variação entre os países em relação à implementação.

Palavras-chave: Padrões. Currículo. Tecnologia. Mapeamento. Livros Didáticos. Pesquisa e Professor de Apoio.

\footnotetext{
"Survey Team Members: Chair: Glenda Lappan (USA), Jiansheng Bao (China), Karen D'Emiljo (Namibia), Keiko Hino (Japan), Vinício de Macedo Santos (Brazil), Malcolm Swan (England), IPC Liaison: Gail Burrill (USA), Graduate Assistant: Funda Gonulates.

"Specialist in the Program in Mathematics Education (PRIME) at Michigan State University, city of the East Lansing, state of the Michigan, US. E-mail: burrill@ msu.edu.

${ }^{* * * *}$ University Distinguished Professor in the Program in Mathematics Education(PRIME) at Michigan State University, city of the East Lansing, state of the Michigan,US. E-mail: glappan@ math.msu.edu.

***** Graduate Students in the Program in Mathematics Education (PRIME) at Michigan State University, city of the East Lansing, state of the Michigan, US. E-mail: fgonulates@gmail.com.
} 


\section{Introduction}

This report is based on an analysis of responses to survey questions on curriculum standards and goals from 11 countries: Australia, Brazil, Egypt, England, China, Honduras, Indonesia, Japan, Namibia, Peru, and six states in the United States ${ }^{1}$. This paper is organized in five sections: standards/curricular goals; relation of standards to the status quo, the role of textbooks in enacting the curriculum, the role of technology in classrooms, and teacher support related to standards/curricular goals ${ }^{2}$. The intent of the report is to allow others to examine their standards/curriculum goals in relation to those of other countries across the world.

\section{Standards/Curricular goals}

Who is responsible for the development of standards/curricular goals?

In most countries the ministry of education establishes curricular standards. In the United States, however, control of education is the state's right, and in many states, for example, Montana, state constitutions give control of education to local districts. The federal government influences education through funding initiatives, such as the No Child Left Behind Act in 2001. The 2010 Common Core State Standards (CCSS) initiative is not a federal program but has been adopted and is being implemented by 45 out of the 50 states and the District of Columbia. China also does not have a mandated national curriculum. China Mainland, including Shanghai, has common standards; Hong Kong, Taiwan and Macau create their own standards/curriculum goals.

In many countries, standards/curricular goals are set by historical tradition or cultural norms. For example, Namibia used the Cambridge curriculum when they became independent in 1990 and only recently began to develop their own standards. Brazil's standards are attributed to the history of the discipline, the prescribed curricula, and the comparative analysis among national documents from different historical periods and national and international documents. Some countries base their standards and guidelines on those of countries with high achievement scores on recent international exams. For example, both England and the United States cite countries such those from the Pacific Rim and Finland as

\footnotetext{
${ }^{1}$ See end of report for list of response teams from each country.
} 
resources for their new standards. Peru noted that an analysis of documents from other countries in South America and from TIMSS, Programme for International Student Assessment (PISA), and National Council of Teachers of Mathematics (NCTM) contributed to the development of their Diseño Curricular Nacional (CND) (National Curricular Design) (2009).

Why standards?

Over time, many countries have changed from local standards to national standards. For example, Brazil found that the lack of national standards contributed to unequal opportunity for education. For much the same reason, the documented difference in the rigor and quality of individual state standards, the state governors in the United States supported the development and adoption of the CCSS. The new US standards are intended to be substantially more focused and coherent.

Standards are viewed as political: i.e., Brazil suggests that mathematics curricular goals depend more on political timing, election campaigns, and government administrations, where "the logic of an education agenda that transcends governments and politicians' mandates, set as a goal for a democratic and developed society, is not the rule" (Response to ICME 12 Curriculum Survey, 2011, p. 6). In the United States the two major political parties have different views on education, its funding, and its goals. This has recently given rise to the creation of publicly funded schools governed by a group or organization with a legislative contract or charter from a state or jurisdiction that exempts the school from selected state or local regulations in keeping with its charter. Hong Kong also reported that writing standards seems to be more politically based than research based. Many of the changes in England's National Curriculum (NC) are the result of criticism from the current government that the NC is over-prescriptive, includes non-essential material, and specifies teaching methods rather than content. In Peru, each new curricular proposal is viewed as an adjustment to the prior curriculum. In this process, radical changes do occur, such as changing the curriculum by capabilities (CND, 2005) to the curriculum by competencies (CND, 2008) in the secondary education level. These decisions are often the result of a policy change with each new government.

In most countries surveyed, a diverse team, including mathematics education researchers, ministry of education staff, curriculum supervisors, and representatives of boards of education are responsible for developing the standards/goals. In some countries (Japan, Australia) teachers are involved, but in others the design teams are primarily experts from universities, teaching universities or the ministry of education (Indonesia, Egypt). The design 
of the framework for the National Curriculum in England is carried out by a panel of four, not necessarily mathematics educators, charged to reflect the view of the broader mathematics education community including teachers.

What is the role of research?

Research has different interpretations and meanings in relation to the development and implementation of standards or curricula guidelines. One common response in the surveys was to cite as research the resources used in preparing standards (for example, other countries' standards). In addition, the degree to which research is used in compiling the standards often depends on the vision, perspectives, and beliefs of the team responsible for the development.

The use of research related to student learning in developing standards/curricular goals is not common among the countries surveyed. A typical description of the process was given by Hong Kong, where the development team might do a literature review and refer to documents of other countries, but the process is not necessarily well structured and often depends on the expertise of the team members. England, however, noted that the first version of their National Curriculum (NC) was largely based on the Concepts in Secondary Mathematics and Science project, (HART, 1981) that sought out to formulate hierarchies of understanding in 10 mathematical topics normally taught in British secondary schools based on the results of testing 10,000 children in 1976 and 1977. The NC was also based on the ILEA Checkpoints (1979) and the Graded Assessment in Mathematics (1988-90) projects. The original research-based design of the NC had many unintended consequences. Although the attainment targets were intended to measure learning outcomes on particular tasks, the levels were used to define the order in which topics should be taught, rather than paying attention to the development of concepts over time. The processes of mathematics, originally called "Using and applying mathematics" were defined in a general way related to progressions and levels that made interpretation difficult. As a consequence, the NC was revised several times and as of the summer of 2012 was again in the process of revision.

After a 1996 survey showed that social segmentation in Brazil seemed to be an obstacle to access to a quality education, research led to the development of the National Curricular Parameters in Brazil (1997). The Board of National Standards for Education in Indonesia examined the national needs for education, the vision of the country, societal demands, challenges for the future, and used their findings in developing the curriculum (MINISTRY OF NATIONAL EDUCATION, 2006). 
What is the nature of standards?

In Brazil, Indonesia, Namibia and Peru, the standards/curricular frameworks are general and provide overarching guidelines for the development of discipline specific content. In the United States, Australia, and Japan, the mathematical standards essentially stand alone, although supporting documents may illustrate how the maths standards fit into the larger national education philosophy and perspective. Some standards include process goals. For example, Australia includes standards for four proficiencies (understanding, fluency, problem solving, and reasoning) based on those described in Adding It Up (KILPATRICK; SWAFFORD; FINDELL, 2001). The new Australian standards want students to see that the mathematics is about creating connections, developing strategies, and effective communication, as well as following rules and procedures. The United States CCSS has mathematical practice standards specifying eight "habits of mind" students should have when doing mathematics. In Brazil ideas such as "learn to learn", "promote independence", "learn to solve problems" are being incorporated into new curricula. In Peru the emphasis is primarily on the processes of problem solving, reasoning and proof, and mathematical communication.

In some cases standards reinforce the role of education in responding to the needs of the country. For example, the Curriculum for Basic Education $\left(1^{\text {st }}-9^{\text {th }}\right.$ grade $)$ in Honduras (DEPARTMENT OF EDUCATION, 2003) was developed under three axes: personal, national and cultural identity, and democracy and work. The four pillars of lifelong learning defined by Delors (2006) (personal fulfilment, active citizenship, social inclusion, and employability/adaptability) were used to define the mathematical content and methodological guides with problem solving as the central umbrella. Namibia's National Curriculum for a Basic Education outlines the aims of a basic education for the society of the future and specifies a few very general learning outcomes for each educational level (MOE, 2008).

Standards span different sets of school grades or levels and differ in generality. Some countries have grade specific standards for what students should know throughout their primary and secondary schooling (i.e., US, Japan). Australia specifies a common curriculum for grades 1-10 and course options for students in upper secondary. Egypt and Honduras have curricular goals for students in grades 1-9 (age 14). At the high school level, Honduras focuses on post high school preparation with more than 53 career-focused schools for students.

The development of fractions in Australia by the Australian Curriculum and Assessment Reporting Authority (ACARA, 2011), the Japanese Ministry of Education, 
Culture, Sports, Science and Technology (MEXT, 2008), the Ministry of Education in Namibia (MOE, 2006), and the US (CCSS, 2010) illustrates the difference in standards across countries. In grade 1, the standards/goals in the US, Namibia and Australia introduce words such as half, quarter and whole; this happens in grade 2 in Japan. Both US and Japan treat fraction as a number on the number line beginning in grade 3 , emphasize equal partitioning of a unit and consider a fraction as composed of unit fractions: $4 / 3=4$ units of $1 / 3$. Australia suggests relating fractions to a number line only for unit fractions in grade 3 , while Namibia does not mention fractions in relation to the number line. Equivalent fractions are taught in grade 4 in US, Japan, and Australia and in grade 6 in Namibia. Addition and subtraction of fractions with like denominators occurs in grade 4 in Japan, with unlike denominators in grade 5 in the US and Japan, and grade 7 in Namibia and Australia. Australia and Namibia have fractions as parts of collections in grade 2 and again in grade 4 in Namibia, but fractions as subsets of a collection are not mentioned in the standards/goals in the US and Japan. Students are expected to multiply and divide fractions in grade 5 in the US (with the exception of division of a fraction by a fraction, which happens in grade 6), in grade 6 in Japan, and in grade 7 in Australia and Namibia.

The next section describes what is taught in classrooms and how this relates to the standards/curricular goals of the country.

\section{Examining the status Quo}

\subsection{How are standards/goals related to the implemented curriculum?}

Standards play different roles in shaping curriculum. For example, as described above, Peru does not have National Standards, but the mathematics learning goals for students are set out in the Curriculum National Design. With this as a guide, each of the country's regions develops a regional curriculum that considers the diversity of cultures and languages. Similarly, since 2005 Indonesia has National Standards for Education, which includes standards for content in each subject area. Based on these and competency standards, every school develops their own curriculum considering the vision of the school, local culture, and students' background. In many of the US states, for example Massachusetts, standards provide a framework with the details of the curriculum, including the materials used for teaching and learning established at the district and school level. Japanese schools base their curricula on the national Course of Study (CS), a "Teaching Guide," resources and guidelines 
developed by local boards of education in the prefecture, and planning guides from textbook companies. Adaptions are sometimes made based on the situation of the school and its students. When the prefectural or the municipal boards of education develop their own model plans, such as the "nine year schooling system" (ShoChu-Ikkan-Kyoiku), the school in the prefecture or the municipality follows those plans and makes revisions to the CS accordingly.

In some instances, countries turn to other countries with more resources for support in implementing the standards. For example, the Japan International Cooperation Agency supported Honduras in developing curriculum and resources for teachers. Macau uses resources from China Mainland, Hong Kong, and Canada.

What drives the implemented curriculum?

Standards, textbooks, or high-stakes examinations seem to drive what happens in classrooms in the countries surveyed. While Hong Kong indicated that standards play that role, teachers in Brazil, Taiwan, Egypt, Honduras, and Japan rely on textbooks, and China mainland cited both textbooks and practice books.

In several countries high stakes examinations are significant in determining what teachers actually teach. In the United States, with the exception of Montana, the states surveyed indicated they followed the curriculum based on the state standards, but in reality most teachers teach only to what they know from experience will be tested. The implemented curriculum in England also seems to be shaped by what is assessed, which determines the nature of the tasks students meet in classrooms. The curriculum in Indonesia is determined both by textbooks and the national examination. Entrance examinations of leading universities impact the curriculum in Brazil and Macau $(95 \%$ of the students in Macau attend private schools to prepare for university).

How do countries monitor implementation of the curriculum?

Countries use several strategies for monitoring and evaluating the enacted curriculum: large scale research studies conducted by the government or a private agency, small focused research studies on what is being taught and learned, student achievement on high stakes assessments, and approval of textbooks teachers use to deliver the curriculum. Relatively large-scale research studies on students' achievement are carried out in Honduras under the auspices of the Inter-American Development Bank and USAID. The Ministry of Education in Brazil investigated the incorporation of the National Curricular Parameters (PCN) into textbooks and other materials supporting teachers' work, but little research has been dedicated to any of the various stages in the process of curriculum development including the curriculum enacted in classrooms. 
Japan administers national assessments on a regular basis in mathematics and Japanese for students in the sixth year of elementary school and the third year of lower secondary school. The results often reveal challenges in knowledge and skill utilization, which leads to revisions in educational policies and classroom lesson plans. These assessments are viewed as invaluable in monitoring and revising the curriculum.

In the United States, perhaps the most significant change in the last decade has been the increasing role of high stakes assessments measuring student achievement in elementary /secondary education. Every year each state assesses each student in grades 3 to 8 and assesses students once in grades 9-12 using a common state assessment, typically consisting of multiple-choice procedural questions. The results are used to evaluate teachers, administrators, and the curriculum. Little or no evidence exists correlating success on these tests with curriculum (or any other factor). This has not deterred federal and state levels policy makers from making use of the assessment results in these ways. The emphasis on high stakes assessment and accountability are seen in England as well, although it is not clear that the results have contributed to changes in the curriculum or standards.

How are changes made to the standards/curricular goals?

Change occurs in different ways. In the US, the most recent change was brought about by entities outside of the government and teachers. Japan bases changes in goals/standards on research examining student learning. Standards teams summarize, examine, and investigate the results of research studies on what has been achieved through the current Course of Study (CS) and the results of pilot trials of new goals/standards in designated "research schools" (Kenkyu-Kaihatsu-Gakko). They monitor emerging trends, societal needs, and international assessments. For example, the most recent revisions to the CS in Japan for elementary and lower secondary schools were in March 2008 and for upper secondary and special needs education in March 2009. In this CS, the aim of mathematics education stresses the student's abilities to express their thinking and to utilize mathematics in daily social life. In the CS for lower secondary schools, a new curricular strand "Use of Data" was added to enrich the content of statistics in the compulsory education. International mathematics assessments have helped statistics become a requirement in upper secondary schools. Taiwan and Hong Kong use some research supported by the government to construct and modify the curriculum as well as to inform teacher professional development and resource materials.

\section{The role of textbooks}


Survey responses indicated commercial publishers, private organizations, and government related organizations were involved in textbook development and distribution but to different degrees. The use of supplementary materials or teacher created worksheets was common in many of the countries. Many countries mentioned national standards/curricular guidelines as tools used in textbook development.

What is the approval or vetting process for textbooks?

In most of the countries with the exception of England and some of the states in the United States, some formal approval is necessary before texts can be used. For example, in Japan, textbooks are edited for adherence to the national curriculum and must be examined and authorized by MEXT. However, each textbook company can design and develop a textbook series with a final draft submitted to MEXT for examination and subsequent revision. During the development process, professionals (such as university researchers and teachers) play a large role in textbook design and development.

Many countries (China, Indonesia, Australia) have multiple textbook options for each grade level. Textbook adoption procedures vary, with decisions made at the national level (Brazil), state level (North Carolina), district level (Japan for elementary and lower secondary), school level (Japan for upper secondary) or even at an individual level (Taiwan). For the most part, the content would be the same across textbook options for each grade level since standards were the main drivers of the textbook development. Textbooks differ in the extent to which the contents are ordered and compiled but often have a similar style. Teachers in England make less use of textbooks than many other countries, and there is no uniform adoption procedure (ASKEW et al., 2010). In addition, public examination bodies produce textbooks that contain exercises from compilations of past examination questions that are popular with British teachers who see them as preparation for high-stakes assessments.

What is the role of research in the development of textbooks?

Most countries mentioned an indirect or no use of research in textbook development. In the United States and England textbooks that are developed through large projects typically involve some research. In the United States, some curriculum materials (such as CMP (2012)) are research-based and developed with government or other sources of funding. Designers study trialling in classrooms, identify issues that emerge, what is working and not working to inform the next iteration of materials. The cycle may have several iterations, depending on funding and on commercial sales. (If the materials market poorly, the development is quickly terminated.) 
Textbooks authored by individual teachers or commercial publishers did not seem to be noticeably influenced by pilot studies, research or research related to learning. In organizing textbook content, Japan makes use of research on high stakes assessments (the National Assessment of Academic Ability and other assessments implemented by local governments), the content and sequence of the old textbooks, and information obtained from teachers on the usability of the textbook and on the students' responses to the textbook problems during the lesson. In Brazil, some authors of mathematics textbooks use research or rely on research results, to develop books.

Focused research projects on aspects of the curriculum, supplements to illustrate the standards, pilot studies of initiatives, action research and/or small seed projects are common in Hong Kong and Japan. In the United States, research studies on student learning typically focus on specific content areas or the development of a single concept, such as understanding cardinality (i.e. Clements (2012)) and have little direct connection to the curriculum. Graduate students carry out many such projects in the United States and in other countries such as Brazil, England, and Australia.

\section{The role of technology in the curriculum}

What is the relationship between standards/curricular goals and technology?

From a broad perspective, interacting with technology is seen in most countries as a critical life skill. In Peru, for example, the aim is to develop students' "skills and attitudes that will enable them to use and benefit from ICT [...] thus enhancing autonomous learning throughout life" (MOE, 2009, p. 17). The National Curricular Parameters (1997) in Brazil cite the value of technology as important for preparing students for their work outside of school. Australia defines Information and Communication Technology (ICT) as one of seven basic capabilities, i.e. the "skills, behaviours and dispositions that, together with curriculum content in each learning area and the cross curriculum priorities, will assist students to live and work successfully in the twenty-first century" (AU, 2012, p. 10) Namibia has much of the same statement in their National Curriculum for Basic Education emphasizing creating and learning to use software such as Word or Excel. Hong Kong's Technology Learning Targets calls for technology to enhance learning and teaching; provide platforms for discussions; help students construct knowledge; and engage students in an active role in the learning process, understanding, visualizing and exploring math, experiencing the excitement and joy of learning maths. 
Some countries such as Namibia and Peru do not outline how technology should be used in the mathematics curriculum. Others describe the use of technology in mathematics classrooms in very general terms. Indonesia, for example, calls for the use of technology to develop understanding of abstract ideas by simulation and animation. In mainland China, the Nine Year Compulsory Education Mathematics Curriculum Standards emphasizes the use of technology to benefit student understanding of the nature of mathematics. In Macau the standards call for educators to consider the impact of computers and calculators on the content and approaches in mathematics teaching and learning. In Taiwan, technology should support understanding, facilitate instruction, and enhance connections to the real world. England's curriculum documents are more specific, consistently encouraging the use of appropriate ICT tools to solve numerical and graphical problems, to represent and manipulate geometrical configurations and to present and analyse data.

The standards/curricular goals of some countries provide general goals for incorporating technology into the curriculum and then describe specific instances. For example, the United States Common Core State Standards (2010) for mathematical practices call for students to visualize the results of varying assumptions, exploring consequences, and comparing predictions; engage students in activities that deepen understanding of concepts; create opportunities for and learning - comparing and contrasting solutions and strategies, creating patterns, generating simulations of problem situations. These generalizations are followed by statements throughout, such as in grade 7, "Draw (freehand, with ruler and protractor, and with technology) geometric shapes with given conditions" (COMMON CORE STATE STANDARDS FOR MATHEMATICS, 2010, p. 50) or in algebra, "find the solutions approximately, e.g., using technology to graph the functions, make tables of values, or find successive approximations" (COMMON CORE STATE STANDARDS FOR MATHEMATICS, 2010, p. 66). The new Australian Mathematics Curriculum specifically calls for the use of calculators to check solutions beginning in grade 3 and, by year10, includes general statements about the use of technology, "Digital technologies, such as spreadsheets, dynamic geometry software and computer algebra software, can engage students and promote understanding of key concepts" (AU, 2012, p. 11). The curriculum provides specific examples: i.e., students should "Solve linear simultaneous equations, using algebraic and graphical techniques including using digital technology" (AU, 2012, p. 61).

Japan has explicit learning goals for the use of technology and its Course of Study provides a guide for teachers that describes how calculators and computers can be used, with 
specific grade level examples under three headings; (1) as tools for calculation, (2) as teaching materials, and (3) as information/communication networks.

How is technology used in classrooms?

Respondents cited general issues related to the use of ICT. In England, for example, inspection reports based on evidence from 192 schools between 2005 and 2007 criticized schools' use of ICT, finding that effective usage was decreasing and the potential of ICT to enhance the learning of mathematics rarely realized. In Brazil, the number of schools equipped with technological resources is increasing, however, programs using the technology are still restricted to pilot projects.

In Japan a 2010 survey on ICT facilities found that computers (98.7\%), digital cameras $(98.1 \%)$, and CD players $(95.2 \%)$ were used almost daily or at least two to three times a week (MEXT, 2011). Yet, results from international studies such as TIMSS indicated little actual computer use in Japanese mathematics classrooms. At least one computer is typically available in classrooms in Egypt, Peru, China mainland and Macau but rarely used for mathematics instruction. Honduras has a one laptop per child program, but the lack of suitable mathematics related activities limits the use of laptops in classrooms. This was also identified as a problem in England. Brazil reported that a preliminary analysis of research conducted in the country suggests that technologies are used very little. Teachers are uncomfortable with laptops and have few resources for using them.

The availability of technological tools for students varied among countries and within countries. Some have class sets of calculators available; others expect students to provide their own (China Mainland, Macau, Hong Kong). Some schools have computer labs; some have class sets of laptops, while others use a single computer with overheard display (common in China Mainland). Many schools in England have a separate computer suite, where pupils learn to use ICT as a mathematical tool, for example using spreadsheets to generate number patterns or present statistical information, but their use to enhance mathematics learning is limited.

Some use computers to provide practice procedures and skills (England, Macau, North Carolina). Some (China mainland, Taiwan, North Carolina) use technology as a way to differentiate instruction. North Caroline describes using interactive sites that allow the learner to manipulate data and objects and then provide immediate feedback; video games, and other learning activities for struggling students, and providing advanced students with online activities that challenge and invite further learning; real world math practice using tools like Google Earth for measurement, stock market simulations, digital cameras for capturing real- 
life examples of geometric figures, Skype or other conferencing tools to interact with scientists and mathematicians. Formative and summative assessment was also indicated as a way of bringing technology into the classroom.

Interactive whiteboards are becoming increasingly common, although their role in learning mathematics is not well documented. They are heavily used in Great Britain (in about $75 \%$ of schools) (SCHACHTER, 2010), and the usage is growing in Japan from 16,403 in 2009 to 60,474 in 2011 (MEXT, 2011) and in the United States with 51\% of classrooms (GRAY; THOMAS; LEWIS, 2010). According to England an advantage of interactive white boards are high-quality diagrams and relevant software to support learning through, for example, construction of graphs or visualization of transformations. A negative effect of interactive whiteboards seemed to be a reduction in pupils' use of concrete manipulatives.

\section{Teacher support}

What support is provided to teachers to help them know the curriculum?

Brazil and Egypt indicated minimum support is provided to teachers to help them learn about the curriculum. Brazil noted the materials are distributed to teachers usually without any actions involving the teachers. The other countries surveyed provide some form of support for teachers although the amount and form as well as who was in charge of providing support differs. Some countries (i.e., England, China, Japan) have ministry driven efforts to help teachers learn about the curriculum. For example, in Japan, once a new course of study (CS) is determined, the Ministry of Education, using a "trainer of trainers" process, conducts "transmission lectures" (Dentatsu-Koshu) on the principles and content of the new CS to superintendents on the prefectural boards of education who in turn give lectures to the superintendents on the municipal boards of education. The local superintendents then give lectures to all schoolteachers within a period of three years. The Ministry makes information available to teachers by showing concrete teaching examples, especially for large changes from an old to a new course of study. A variety of research meetings and conferences as well as lectures and symposiums are offered to educate teachers on the new CS.

A similar trainer of trainers process organized by the Ministry is also used in Honduras and Peru, although in Peru, some question the effectiveness of the process, given the results of five evaluations available on the web page of the Ministry of Education. Since 2010 the Ministry of Education in Mainland China has invested considerable resources to help teachers (over 1.1 million teachers at the primary level) understand the basic ideas of the 
curriculum standards and main content of the curriculum. The work is organized and financed by the Ministry but carried out at the local level. In Hong Kong, the Ministry of Education organized a professional development series, "Understanding the Curriculum", to explain the breadth and width of the curriculum. Exemplars, usually a product of collaborative research with schools, are used for illustration.

Other countries have a blend of ministry designed strategies and local initiatives. In Indonesia, the local (district and province) as well as central governments facilitate in-service training for teachers helping them to understand more about the curriculum. District school supervisors, advisors and/or experts from universities give the training and aim to improve the understanding of the Standards of Content, Process and Evaluation.. Workshops and sessions on the standards are often organized and provided at the local level by university educators, school districts, curriculum consortia, and non-profit partners for all educators in a region of a state. Web based resources are provided in several countries (Honduras, China Mainland, Hong Kong, Japan). North Carolina provides webinars on the structure, organization, and content of the state standards, and Ohio provides online resources and disseminates curriculum models and other support documents to districts.

What support is provided to teachers to help them enact the curriculum?

In some countries support for instruction related to curriculum comes from the ministry of education (China Mainland, Hong King, England, Peru, some states in the United States) and in others it is provided through a combination of ministry of education and local initiatives or at the local level. Support primarily takes three forms: resources, professional development, and mentoring.

1) Resources: Supplemental resources, materials created by outside research-based projects, and documents based on the state/national curriculum or standards are often designed and delivered through university programs. In some areas in Brazil, teachers are given written supporting material, videos, and learning resources, and technical pedagogical teams often help teachers in the implementation of the curriculum.

2) Professional Development: A variety of forms of professional development were also cited as ways to help teachers enact the curriculum. In Taiwan the curriculum development council provides lectures at the school level, instruction counselling groups and in-service workshops. Teacher training in Indonesia helps teachers develop teaching plans and provides strategies, methods, and approaches that have been adopted from the current research and theory. Honduras uses a "learn by doing" model for in-service, and many districts in the United States support mathematics "learning communities". Some form of 
collaborative lesson planning is typical in several of the countries (Japan, Macau, some states in the United States). In many countries (i.e., Hong Kong, United States) universities offer a variety of programs for in-service teacher education; graduate programs are also sites for teachers' professional development. Publishers also organize and deliver professional development workshops (China Mainland, United States).

Japan has a structured system of support. Local boards of education provide training for beginning teachers and for those with five, 10 and 20 years of teaching experiences as well as a variety of professional, non-mandatory training courses to enhance teaching ability and skills; for example, the Tochigi prefectural board of education offers 50 courses a year. Recently, a new teacher training/licensing system has been employed. Ordinary and special licenses are valid for 10 years; teachers need to renew their licenses by attending training courses every 10 years, given by general universities and teacher-training universities. These training courses are required to offer information based on the most recent research.

3) Mentoring: A third form of support in some countries is individualized, such as the Strategic Program for Learning Achievements in Peru where, since 2010, classroom teachers working with children up through the first two years of Basic Education (grades 6-8) receive advice from a specialist teacher. In the United States, many local districts have mathematics coaches who work with teachers, particularly at the elementary level. Hong Kong has dedicated "research schools" that mentor other schools in the implementation of the curriculum. A slightly different strategy is used in Honduras where teachers travel to Japan to see how the curriculum is enacted in classrooms and to learn about mathematics education.

While some cite a research base for professional development, the connection to research is often very limited (Hong Kong, Massachusetts and North Carolina in the United States). England provided ministry organized teacher support designed with a research perspective and later studies investigated the success of the implementation. The National Strategies (DFE, 2011) were, from 1998 until 2011, the main delivery vehicle for supporting teachers to understand and implement government teaching and learning priorities. The programme, originally called the National Numeracy Strategy (NNS), was aimed at primary education but was later expanded to include secondary schools with the National Mathematics Strategy (NMS). The National strategies conducted a massive professional development programme, running courses and providing publications, advice, and professional development materials such as videos to schools. These also included guidance on course planning, teaching and learning, assessment, subject leadership, inclusion, intervention and mathematics specific content. Detailed assessment guidance, lesson plans, and intervention 
programs were all provided (DFE, 2011). An annotated bibliography of research evidence claimed to underpin the National Strategies (REYNOLDS; MUIJS, 1999). However, the research evidence was described as ambivalent and relatively scarce (BROWN et al., 2003).

Evaluations of the implementation of the NNS were carried out and indicated some success, but this was contested by many who asserted that the gains on National Tests attributed to the programme may be attributed to a careful choice of statistical baselines and teachers increasing tendency to orient their teaching towards the tests. When alternative tests were used, smaller gains were noted. Teaching seemed to have changed mainly in superficial ways, and some evidence suggested that in almost no cases were there 'deep' changes. (BROWN et al., 2003, p. 668). In 2008 an inspection service found weaknesses in basic teaching skills and had difficultly assessing which initiatives worked and which did not. The frequent introduction of new initiatives, materials, and guidance led to overload and diminished the potential effectiveness of each individual initiative (OFSTED, 2010). As of March 2012, the Coalition Government abolished the National Strategies programme, and future professional development is decentralized and in the hands of individual schools.

\section{Concluding remarks}

The survey data shows us that a common set of mathematics learning goals are established in almost all countries with a very minor role for research in designing and monitoring the development of their curriculum. Standards, textbooks, or high-stakes examinations seem to drive what happens in classrooms. Countries vary greatly in the amount of support provided to teachers in learning about and implementing the curriculum specified in their standards/goals.

\section{Survey Responders}

Australia: Peter Sullivan (Monash University).

Brazil: This report is a result of the collaboration between the Group of Studies and Research on Mathematical Education and Education (USP) \& Organization, Curriculum Development and Teacher Education (PUCSP).

Vinício de Macedo Santos (University of Sao Paulo).

Célia Maria Carolino Pires (Pontifícia Universidade Católica de São Paulo).

Elenilton Vieira Godoy (Pontifícia Universidade Católica de São Paulo and Centro Universitário Fundação Santo André).

João Acácio Busquini (Secretaria de Estado da Educação de São Paulo). José Carlos Oliveira Costa (Centro Universitário Fundação Santo André). 
China: China Mainland - Jiansheng Bao, Xuefen Gao, Likun Sun \& Xiaoli Ju (East China Normal University, Shanghai).

Taiwan: Hsin-Mei E. Huang (Taipei Municipal University of Education).

Hong Kong: Polly Lao (Hong Kong Bureau).

Macau: Chunlian Jiang (University of Macau)

Egypt: Fayez Mina (Ain Shams University).

Honduras: Libni Berenice Castellón (Universidad Pedagógica Nacional Francisco Morazán.).

Indonesia: Edy Tri Baskoro (Board for National Education).

Japan: Keiko Hino (Nara University).

Namibia: Karen D'Emiljo (Otjiwarongo Secondary School) .

Peru: Martha Rosa Villavicencio Ubilus (National University San Marcos); Olimpia Castra Mora (Ministry of Education).

United Kingdom, England: Malcolm Swan, Sheila Evans (University of Nottingham).

\section{References}

ASKEW, M.; HODGEN, J.; HOSSAIN, S.; BRETSCHER, N. Values and variables: Mathematics education in high-performing countries. London: Nuffield Foundation, 2010.

AU, W. High-stakes testing and curricular control: A qualitative metasynthesis. Australian Curriculum and Assessment Reporting Authority. The Australian Curriculum: Mathematics, 2012.

Australian Curriculum, Assessment and Reporting Authority (ACARA). Annual Report 2010-2011. 2011. Available in: <http://www.acara.edu.au/verve/_resources/ACARA_Annual_Report_20102011.pdf> . Accessed at: 31 Oct. 2011.

BRASIL. Secretaria de Educação Fundamental. Parâmetros Curriculares Nacionais: Matemática (National Curriculum Parameters: Mathematics). Secretaria de Educação Fundamental. Brasília: MEC/SEF, 1997.

BROWN, M.; ASKEW, M.; MILLETT, A.; RHODES, V. The key role of educational research in the development and evaluation of the National Numeracy Strategy. British Educational Research Journal, London, v. 29, n. 5, p. 655-667. Oct. 2003.

BROWN, M. L. (Ed.). Graded Assessment in Mathematics development pack: teacher's handbook. United Kingdom: Basingstoke Hants: Macmillan Education, 1988.

CLEMENTS, D. Address at the Association of Mathematics Teacher Educators Annual Meeting. Texas: Fort Worth TX, 2012

COMMON CORE STATE STANDARDS. Council of Chief State School Officers \& National Governor's Association. 2010. Available in: <http://www.corestandards.org/wpcontent/uploads/Math_Standards.pdf>. Accessed at: 10 Oct. 2011.

CONNECTED MATHEMATICS PROJECT. 2000. Available in: 〈http://connectedmath.msu.edu>. Accessed at: 18 Oct. 2011.

DEPARTMENT OF EDUCATION HONDURAS. Currículo National Básico. 2003. Available in: <www.se.gob.hn/index.php?a=Webpage\&url=curriculo>. Accessed at: 01 Oct. 2011. 
DELORS, J. Learning: The treasure within. Report to UNESCO of the International Commission on Education for the Twenty-first Century. Paris: UNESCO, 1996.

DFE. The National Strategies. 2011. Available in: 〈http://nationalstrategies.standards.dcsf.gov.uk/>. Accessed at: 11 Oct. 2011.

DISEÑO CURRICULAR NACIONAL. (National Curricular Design). Lima, Peru: Ministry of Education, 2005.

DISEÑO CURRICULAR NACIONAL. (National Curricular Design). Lima, Peru: Ministry of Education, 2008.

DISEÑO CURRICULAR NACIONAL. (National Curricular Design). Lima, Peru: Ministry of Education, 2009.

GRAY, L.; THOMAS, N.; LEWIS, L. Teachers' use of educational technology in U.S. public schools: 2009 (NCES 2010-040). Washington, DC: National Center for Education Statistics, Institute of Education Sciences, U.S. Department of Education, 2010.

HART, K. (Ed.). Children's understanding of mathematics 11-16. London: John Murray, 1981.

INNER LONDON EDUCATION AUTHORITY. Checkpoints assessment cards. Inner London: Education Authority Learning Materials Service, 1979.

KILPATRICK, J.; SWAFFORD, J.; FINDELL, B. (Ed.). Adding it up: Helping children learn mathematics. National Research Council. Washington, DC: National Academy Press, 2001.

MINISTRY OF EDUCATION, CULTURE, SPORTS, SCIENCE AND TECHNOLOGY, JAPAN. Elementary school teaching guide for the Japanese course of study: Mathematics. Tokyo: published by the Japanese Ministry of Education, Culture and Sports, 2008. (English translation Japanese mathematics curricula in the course of study, March, 2008 by Asia-Pacific Mathematics and Science Education Collaborative at DePaul University, Chicago IL, USA).

MINISTRY OF EDUCATION, CULTURE, SPORTS, SCIENCE AND TECHNOLOGY, JAPAN. Results of the survey on the states of educational use of information technology in schools. Tokyo: published by the Japanese Ministry of Education, Culture and Sports, 2011. (in Japanese).

MINISTRY OF NATIONAL EDUCATION.Tentang standar kompetensi lulusan untuk satuan pendidikan dasar dan. Republic of Indonesia. Jakarta: published by the Indonesian Ministry of Education and Culture, 2006. (Competence standards graduates units for basic and secondary education).

NAMIBIA MINISTRY OF EDUCATION. Curriculum for the Lower Primary Phase Grades 1-4. National Institute for Educational Development. Okahandja: published by the Namibian Ministry of Education, 2005.

NAMIBIA MINISTRY OF EDUCATION. Mathematics Syllabus Upper Primary Phase Grades 5 - 7. National Institute for Educational Development. Okahandja: published by the Namibian Ministry of Education, 2006

NAMIBIA MINSTRY OF EDUCATION. National Curriculum for Basic Education. National Institute for Educational Development. Okahandja: published by the Namibian Ministry of Education, 2008. 
OFSTED (Office for Standards in Education, Children's Services and Skills). The National Strategies: A review of impact. 2010. Available in:

$<$ http://www.ofsted.gov.uk/sites/default/files/documents/surveys-and-goodpractice/t/The\%20National\%20Strategies\%20a\%20review\%20of\%20impact.pdf > . Accessed at: 30 Oct. 2011.

REYNOLDS, D.; D. MUIJS. National numeracy strategy: An annotated bibliography for teachers and schools. 1999. Available in:

<http://www.highreliabilityschools.co.uk/_resources/files/downloads/effectiveness/drdm1998a.pdf>. Accessed at: 15 Oct. 2011.

SCHACHTER, R. Whiteboards: Learning from Great Britain. Scholastic Administrator. Available in: <www.scholastic.com/browse/article.jsp?id=3753768>. Accessed at: 27 Oct. 2011.

Submetido em Agosto de 2013. Aprovado em Janeiro de 2014. 